Classification

Physics Abstracts

$61.16 \mathrm{D}-61.40 \mathrm{D}$

\title{
Scanning electron microscopy and $X$-ray energy dispersive spectroscopy studies of defects in lead glasses
}

\author{
Giovanni Valdrè \\ Department of Mineralogical Sciences, Piazza di Porta S. Donato 1, I-40126 Bologna, Italy \\ Centre of Electron Microscopy c/o Dept. of Physics, University of Bologna, I-40126 Bologna, Italy
}

(Received September 25, 1990; accepted February 14, 1991)

\begin{abstract}
Scanning electron microscopy (SEM) observations, quantitative X-ray energy dispersive spectroscopy (EDS) and windowless EDS (WEDS) of typical defects in lead glasses are presented. The micrographs, obtained mainly by means of a high efficiency backscattered electron (BSE) detector, showed the presence of cords of varying shape, diameter $(10-200 \mu \mathrm{m})$ and composition, spherical inclusions and cracks; a high density of low $Z$ deposits were found along and in the proximity of the edges of the cracks. Quantitative microanalyses performed on the cords showed the presence of about $3 \mathrm{wt} \%$ of $\mathrm{Al}_{2} \mathrm{O}_{3}$ and $2 \mathrm{wt} \%$ of $\mathrm{ZrO}_{2}$ originating at the interface between the glass and the refractory materials used to hold the melt, and a Pb content lower than the matrix. A high Pb content was instead found in the spherical inclusions, whereas WEDS showed the presence of $C$ in the deposits. These morphological and microchemical results provide to clarify the mechanisms of defect formation.
\end{abstract}

\section{Introduction.}

The presence in a glassware of defects of size smaller than about $200 \mu \mathrm{m}$ adversely affects the optical quality of the manufact. To improve the fabrication processes of high quality lead glasses a full understanding of the mechanisms of defects formation in the glass is essential. These mechanisms are clarified when a full knowledge of the defect is gathered. Glass defects of various nature have been extensively studied in the past with various techniques such as Optical Microscopy, Gas-Chromatography, Mass Spectroscopy and particularly X-ray Electron Probe Microanalysis (EPMA) [1,7]. Defects such as cords, filaments, impurities and dishomogeneities sometimes develop according to various, uncontrolled, conditions. Since these defects are often present on a microscopic scale, SEM with EDS is one of the techniques available to investigate into these problems. Moreover, the defects are characterized by complex dishomogeneities and crystal chemistries, thus backscattered electron atomic number contrast imaging in the SEM comes into its own [8]. This work presents an example of SEM (particularly in the high efficiency BSE detection mode) and (W)EDS study of an artificial glass of high $\mathrm{Pb}$ content for glassware.

The state of-the-art of the investigation techniques were employed to show the capability of modern SEM and (W)EDS to solve this kind of problems. 


\section{Experimental.}

The glass specimens, supplied by C.A.L.P. (Colle Val D'Elsa, Siena, Italy), were made from a melting process, performed at about $1400^{\circ} \mathrm{C}$, of mainly $\mathrm{SiO}_{2}, \mathrm{~Pb}_{3} \mathrm{O}_{4}, \mathrm{~K}_{2} \mathrm{CO}_{3}, \mathrm{Na}_{2} \mathrm{CO}_{3}, \mathrm{BaCO}_{3}$, $\mathrm{Na}_{2} \mathrm{~B}_{4} \mathrm{O}_{7} \cdot 5 \mathrm{H}_{2} \mathrm{O}$, other minor components and $\mathrm{KNO}_{3}$ as refining agent. During the process the melt was held in a AZS refractory material made of (wt\%) $\mathrm{Al}_{2} \mathrm{O}_{3} 50.6 \mathrm{ZrO}_{2} 32.5 \mathrm{SiO}_{2} 15.6 \mathrm{Na}_{2} \mathrm{O}$ 1.10 and $(\mathrm{MgO}$ and $\mathrm{CaO}) 0.12$.

The resulting mean composition of the glass is (wt\%): $\mathrm{SiO}_{2}$ 59.0, $\mathrm{PbO} 25.6, \mathrm{~K}_{2} \mathrm{O}$ 9.4, $\mathrm{Na}_{2} \mathrm{O} 4.0$, $\mathrm{B}_{2} \mathrm{O}_{3} 0.8, \mathrm{BaO} 0.9, \mathrm{Sb}_{2} \mathrm{O}_{3} 0.24, \mathrm{Al}_{2} \mathrm{O}_{3} 0.04, \mathrm{TiO}_{2} 0.02, \mathrm{ZrO}_{2} 0.02, \mathrm{Fe}_{2} \mathrm{O}_{3} 0.008$.

The samples, having at least one dimension of the order of the $\mathrm{cm}$, presented cord-type defects, both at the surface and in the interior, some of them visible by naked eye. In order to characterize the defects cross-sections were cut perpendicular to the cord axis (specimens referred in the following as A) and at shallow angle (specimens C). Surfacial cords were also examined after a slight lapping parallel to the surface (specimens B). All samples were incorporated in epoxy resins, then lapped and subsequently coated with a carbon film about $30 \mathrm{~nm}$ thick, in order to produce a flat and conductive surface in accordance with the best procedure required for quantitative analyses using standards [9].

A Philips XL SEM and a Philips 515 SEM equipped with an EDAX PV9900 EDS detector were employed for the morphological and microanalytical examination of the glass defects.

An EDAX ECON IV windowless EDS detector was subsequently employed for the detection of low $Z$ elements.

In the SEMs, a BSE detector geometry [10], expecially designed for the detection of high angle BSEs, was used in order to improve the atomic number contrast imaging $[11,12]$.

The microanalyses were carried out by the EDAX-QUAN program, a modified version of the FRAME-C, a program developed by the N.B.S. for quantitative EDS analysis, which uses the method of the standards already amply described in the literature [13]. Mineral standards supplied by the United States National Museum of Natural History (U.S.N.M.), Washington D.C. [14], artificial glass standards supplied by N.B.S. Gaithersburg, MD [15] and C.A.L.P. were used as specified in table I. The quality of the analyses was controlled by making periodic measurements on the reference standards while performing the microanalytical dosages. In addition in some cases $\left(\mathrm{PbO}, \mathrm{SiO}_{2}, \mathrm{BaO}, \mathrm{ZrO}_{2}\right.$ and $\mathrm{Al}_{2} \mathrm{O}_{3}$ ) cross checks were made by using more than one standard.

The SEMs were operating at $30 \mathrm{kV}$ during the SE and BSE observations. Microanalysis was instead performed at $15 \mathrm{kV}$ with a well stabilized probe current of $2.100 \mathrm{nA}$ (the decreasing rate of the probe current was of $0.005 \mathrm{nA} / \mathrm{h}$ ) resulting in about $3000 \mathrm{CPS} \mathrm{X}$-ray count rate.

\section{Results and discussion.}

Figures 1, 2 and 3 are BSE images of cross-sections of three cords (specimen type A). The cords have a typical "galaxy" shape and the dark contrast clearly indicates the presence of elements of lower atomic number $Z$ than the surrounding matrix.

In addition, BSE atomic contrast clearly shows intra-cord dishomogeneities. The quantitative microanalysis (performed on such dishomogeneities and indicated as numbered dots in the figures) are reported in table II. All the analyses performed in the centre of the cords show the presence of $\mathrm{Al}_{2} \mathrm{O}_{3}$ and $\mathrm{ZrO}_{2}$ whose concentration ranges from 3.3 to $3.6 \mathrm{wt} \%$ and from 2.3 to 2.4 wt\% respectively. Moving from the center to the border of the cords, the analyses revealed a concentration gradient for $\mathrm{Al}_{2} \mathrm{O}_{3}$ and $\mathrm{ZrO}_{2}$. In addition, all the analyses showed a $\mathrm{Pb}$ content smaller than in the matrix. These facts explain the low BSE signal of the cords. The cords thus originate 
Table I. - Standards and elecments used for the EDS analyses.

\begin{tabular}{|c|c|c|c|c|c|c|c|c|}
\hline \multicolumn{3}{|c|}{ USNM } & \multicolumn{3}{|c|}{ NBS } & \multicolumn{3}{|c|}{ CALP } \\
\hline Mineral & Elem. & wt\% & Glass & Elem. & wt\% & Glass & Elem. & wt\% \\
\hline Anortho- & $\mathrm{Na}_{2} \mathrm{O}$ & 9.31 & $\mathrm{~N}^{\circ} 89$ & $\mathrm{Na}_{2} \mathrm{O}$ & 5.59 & A & $\mathrm{Na}_{2} \mathrm{O}$ & 4.19 \\
\hline clase & $\mathrm{SiO}_{2}$ & 66.44 & & $\mathrm{SiO}_{2}$ & 65.33 & & $\mathrm{SiO}_{2}$ & 56.43 \\
\hline & & & & $\mathrm{K}_{2} \mathrm{O}$ & 8.32 & & $\mathrm{~K}_{2} \mathrm{O}$ & 8.85 \\
\hline Micro- & $\mathrm{K}_{2} \mathrm{O}$ & 15.14 & & $\mathrm{PbO}$ & 17.44 & & $\mathrm{Al}_{2} \mathrm{O}_{3}$ & 5.80 \\
\hline cline & & & & $\mathrm{BaO}$ & 1.42 & & $\mathrm{ZrO}_{2}$ & 1.43 \\
\hline & & & & & & & $\mathrm{PbO}$ & 20.60 \\
\hline Corundum* & $\mathrm{Al}_{2} \mathrm{O}_{3}$ & 99.99 & & & & & $\mathrm{BaO}$ & 0.93 \\
\hline Zircon & $\mathrm{ZrO}_{2}$ & 66.32 & & & & B & $\mathrm{Na}_{2} \mathrm{O}$ & 4.04 \\
\hline & & & & & & & $\mathrm{SiO}_{2}$ & 58.80 \\
\hline & & & & & & & $\mathrm{K}_{2} \mathrm{O}$ & 9.45 \\
\hline & & & & & & & $\mathrm{PbO}$ & 25.70 \\
\hline${ }^{*}$ synthetic & & & & & & & $\mathrm{BaO}$ & 1.00 \\
\hline
\end{tabular}

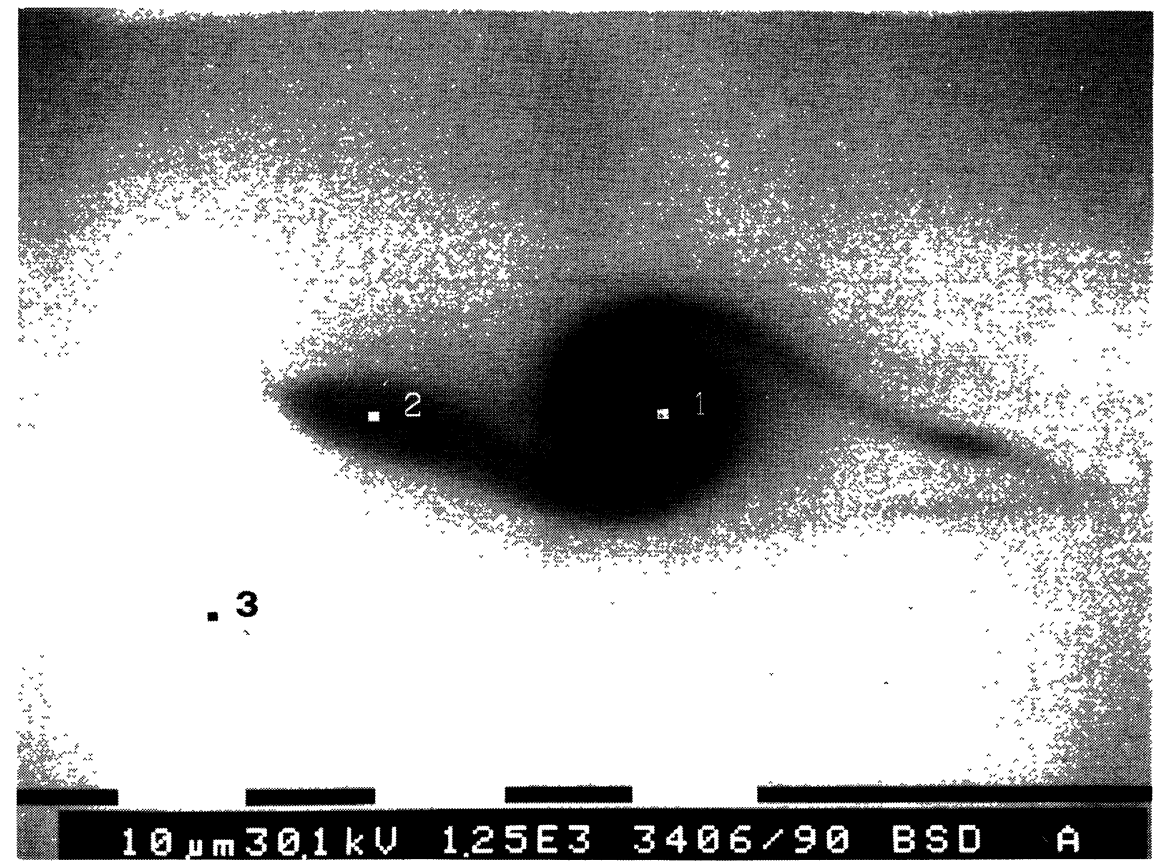

Fig. 1. - Sample type A. BSE image of a cross-sectioned cord showing a typical "galaxy" appearance. Marker $=10 \mu \mathrm{m}$. 

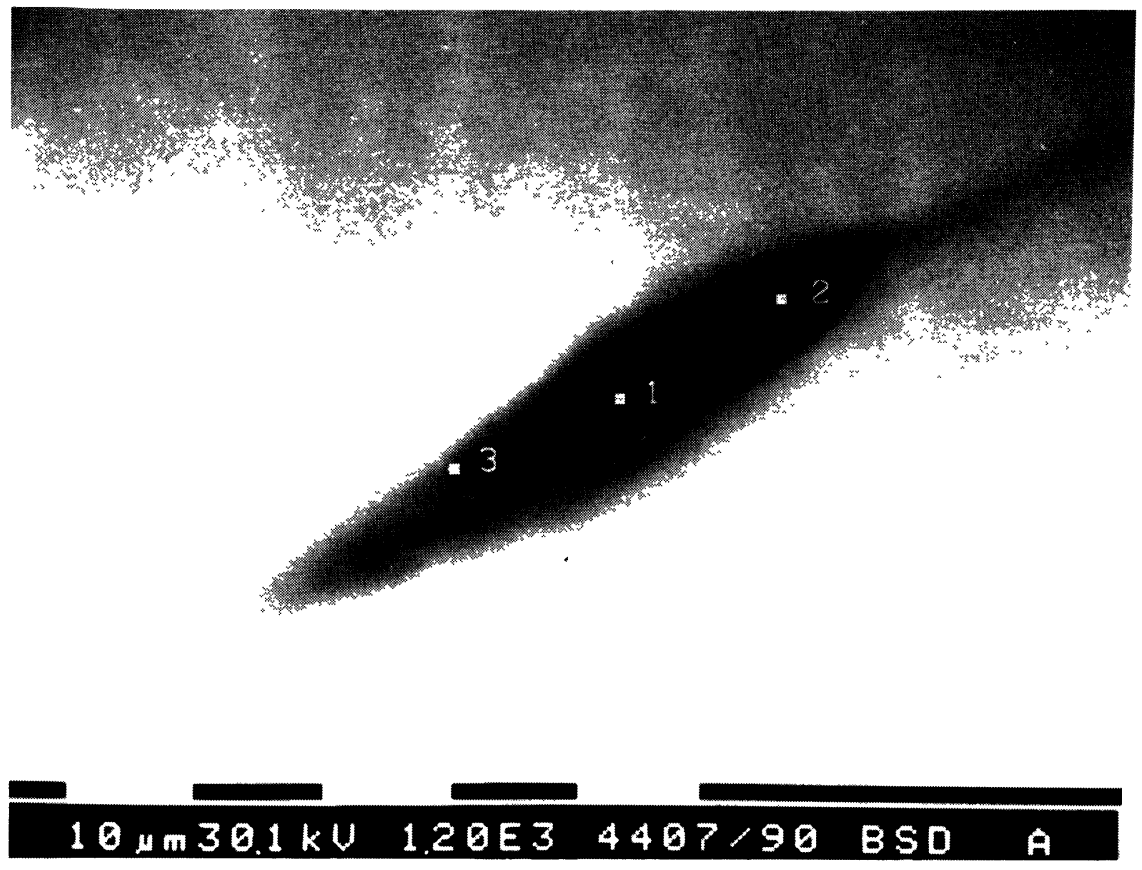

Fig. 2. - BSE image of an elongated "galaxy" in type A sample. Marker $=10 \mu \mathrm{m}$.

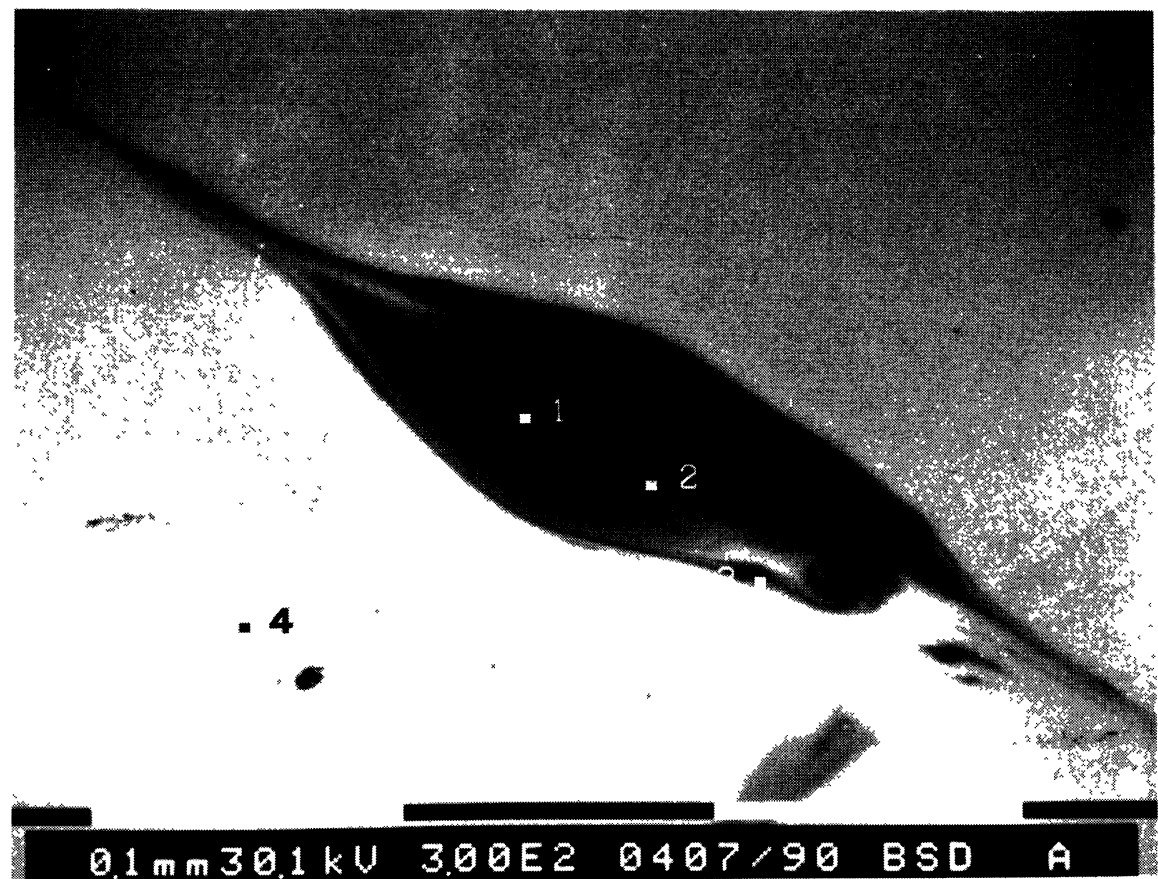

Fig. 3. - BSE image of a dishomogeneous cord in type A sample. The points where microanalyses have been performed are shown. Marker $=100 \mu \mathrm{m}$. 
Table II. - (wt\%) analyses ${ }^{*}$ of points of figures 1,2 and 3.

\begin{tabular}{|c|c|c|c|c|c|c|c|c|c|c|}
\hline Figures & & 1 & & & 2 & & & 3 & & \\
\hline Points & 1 & 2 & 3 & 1 & 2 & 3 & 1 & 2 & 3 & 4 \\
\hline $\mathrm{Na}_{2} \mathrm{O}$ & 2.3 & 2.0 & 2.6 & 1.8 & 1.9 & 1.8 & 2.0 & 2.4 & 2.4 & 2.5 \\
\hline $\mathrm{Al}_{2} \mathrm{O}_{3}$ & 3.6 & 1.7 & - & 3.5 & 2.5 & 2.6 & 3.3 & 1.3 & 3.0 & - \\
\hline $\mathrm{SiO}_{2}$ & 73.8 & 73.2 & 64.5 & 73.3 & 71.0 & 71.1 & 74.5 & 74.8 & 74.2 & 65.6 \\
\hline $\mathrm{K}_{2} \mathrm{O}$ & 7.8 & 6.6 & 6.7 & 8.1 & 7.3 & 7.5 & 8.0 & 6.6 & 7.6 & 6.7 \\
\hline $\mathrm{ZrO}_{2}$ & 2.4 & 1.2 & - & 2.4 & 2.0 & 2.1 & 2.3 & 0.9 & 2.3 & - \\
\hline $\mathrm{PbO}$ & 10.2 & 13.4 & 23.6 & 10.0 & 13.9 & 13.8 & 9.4 & 13.4 & 10.2 & 23.1 \\
\hline $\mathrm{BaO}$ & 0.6 & 0.6 & 0.7 & 0.4 & 0.5 & 0.5 & 0.4 & 0.7 & 0.4 & 0.6 \\
\hline Tot & 100.7 & 98.7 & 98.1 & 99.5 & 99.1 & 99.4 & 99.9 & 100.1 & 100.1 & 98.5 \\
\hline
\end{tabular}

* each value is the average of 3 analyses.

originate from glass-refractory interaction in zones where a fused cast AZS refractory is used. This interaction is very complex and may be interpreted in terms of corrosion and/or exudation of glassy phase from refractory structure. In both cases, the final result is that some glassy phase, enriched in alumina and zircon oxide (originated at the interface glass-refractory), will go into the glass causing knots and, consequently, cords. These knots must have floated, spinned and dissolved in the glass during the process of its fabrication. The "galaxy" shapes and concentration gradients are typical of a spinning motion occuring while chemical dissolution takes place as both the BSE contrast, and the microanalyses, give clearly proofs.

Sample B, as anticipated, was flattened and polished in order to have longitudinal sections of the cords at the specimen surface. Figure 4 is a BSE image where a cord, about $50 \mu \mathrm{m}$ wide, appears in the usual dark contrast.

Spherical inclusions (white dots of about $50 \mu \mathrm{m}$ in diameter, indicating the presence of high $Z$ constituents) are also visible. The place where analyses were performed are indicated by numbered dots on the micrograph and reported in table III. In accordance with the previous microanalytical data, the cord is of the same type of those of sample A. The white dots, on the contrary, are made of high $\mathrm{Pb}$ content, probably due to a local lead reduction. This phenomenon takes place preferentially at the glass surface which is in contact to the refractory material [16].

Figure 5 is a BSE image of a sample prepared according to procedure C. EDS microanalyses were performed on the cord and on the surrounding matrix and marked on the micrograph as numbered dots. They are reported in table IV. In general, all the analyses reflect the tendency found on cross-sectioned cords of sample A, i.e. the presence of elements from refractory materials $\left(\mathrm{Al}_{2} \mathrm{O}_{3}\right.$ and $\left.\mathrm{ZrO}_{2}\right)$ and of a $\mathrm{Pb}$ content smaller than that of the proximal matrix, thus suggesting the same mechanism of formation. 


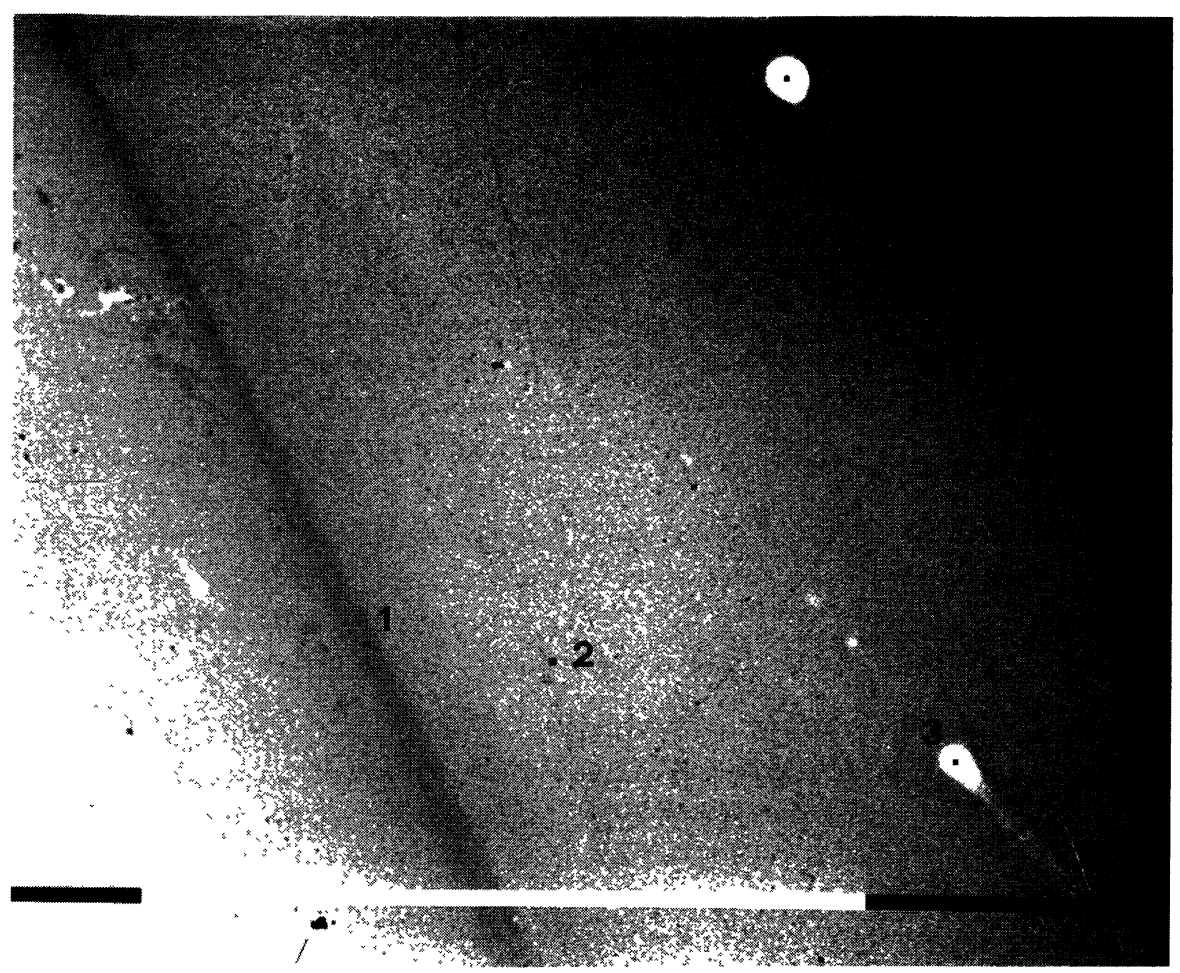

Fig. 4. - Sample type B. BSE image of a surfacial cord. Spherical inclusions producing a high BSE signal are also visible. Marker $=1 \mathrm{~mm}$.

Table III. - (wt\%) analyses* performed in the points of figure 4.

\begin{tabular}{|lrccc|}
\hline Points & \multicolumn{1}{c}{1} & 2 & 3 & 4 \\
$\mathrm{Na}_{2} \mathrm{O}$ & 1.7 & 2.7 & 2.7 & 2.8 \\
$\mathrm{Al}_{2} \mathrm{O}_{3}$ & 2.5 & - & - & - \\
$\mathrm{SiO}_{2}$ & 73.3 & 65.7 & 55.1 & 50.8 \\
$\mathrm{~K}_{2} \mathrm{O}$ & 6.2 & 6.7 & 6.8 & 6.6 \\
$\mathrm{ZrO}$ & 1.9 & - & - & - \\
$\mathrm{PbO}$ & 13.2 & 23.7 & 33.7 & 38.2 \\
$\mathrm{BaO}$ & 0.5 & 0.8 & 0.5 & 0.6 \\
$\mathrm{Tot}$ & 99.3 & 99.6 & 98.8 & 99.0 \\
\hline
\end{tabular}

* each value is the average of 3 analyses. 


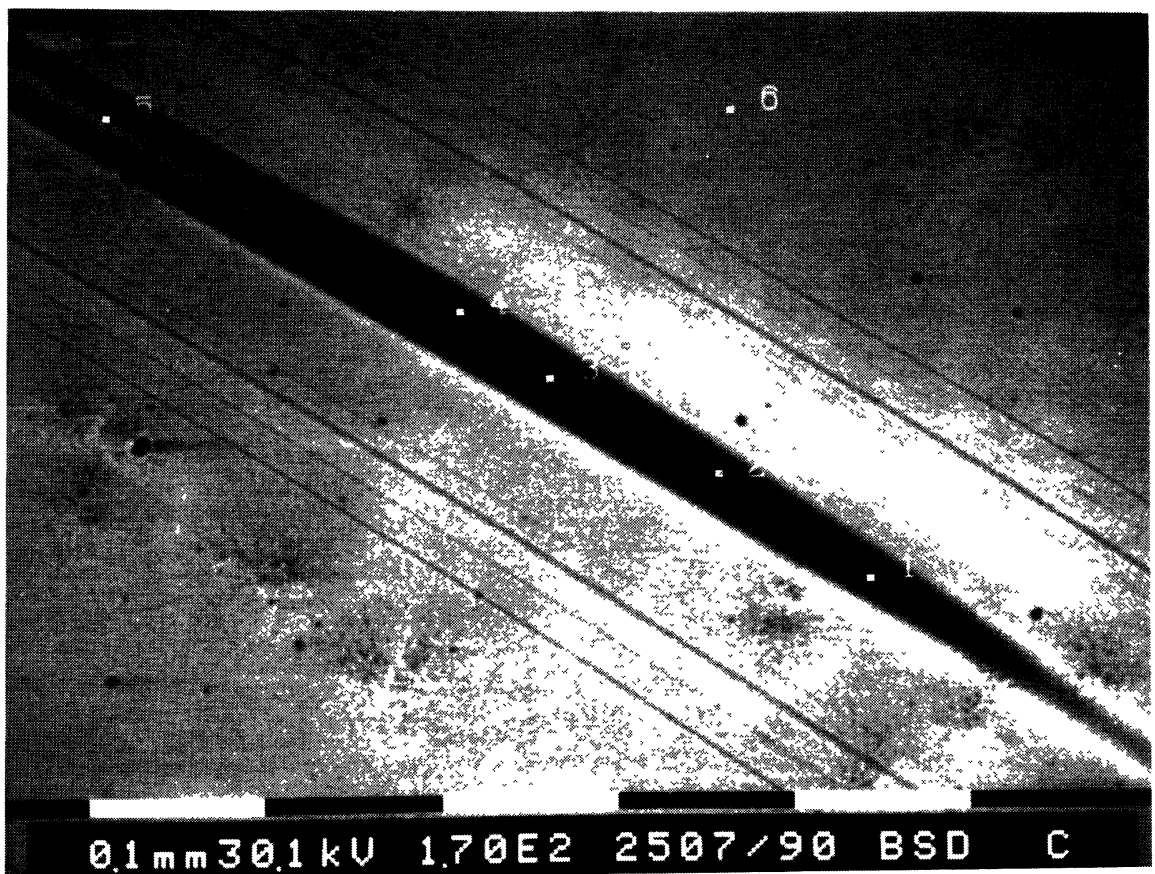

Fig. 5. - Sample type C. BSE image of a shallow angle cross-sectioned cord showing also the corresponding microanalyzed points. Marker $=100 \mu \mathrm{m}$.

Table IV. - (wt\%) analyses* corresponding to points of figure 5.

\begin{tabular}{|lrrrrccc|}
\hline Points & 1 & 2 & 3 & 4 & 5 & 6 & 7 \\
$\mathrm{Na}_{2} \mathrm{O}$ & 2.1 & 2.6 & 2.4 & 2.6 & 2.7 & 2.5 & 2.4 \\
$\mathrm{Al}_{2} \mathrm{O}_{3}$ & 1.7 & 1.7 & 1.6 & 1.2 & - & - & - \\
$\mathrm{SiO}_{2}$ & 65.9 & 65.9 & 65.7 & 65.6 & 64.6 & 65.8 & 65.8 \\
$\mathrm{~K}_{2} \mathrm{O}$ & 7.0 & 7.2 & 7.1 & 7.1 & 7.2 & 7.0 & 6.7 \\
$\mathrm{ZrO}_{2}$ & 1.5 & 1.4 & 1.4 & 1.2 & - & - & - \\
$\mathrm{PbO}$ & 20.7 & 20.9 & 20.5 & 21.6 & 23.8 & 23.4 & 24.4 \\
$\mathrm{BaO}$ & 0.6 & 0.5 & 0.7 & 0.6 & 0.6 & 0.6 & 0.8 \\
$\mathrm{Tot}$ & 99.5 & 100.2 & 99.4 & 99.9 & 98.9 & 99.3 & 100.1 \\
\hline
\end{tabular}

* each value is the average of 3 analyses.

Sample C presented several cracks; the regions nearby the cracks were carefully studied. All five cracks found in the specimens showed lenticular shaped details distributed in rows near and along both sides of the fractures, as can be seen from the typical image reported in figure 6a. BSE imaging (Fig. 6b) showed the presence of elements of low $Z$ whereas WEDS microanalysis (Fig. 7) recorded high Carbon signal from such details. Occasionally, isolated lenticular details were found in regions not associated with fractures or in samples without fractures at all. The origin of these features and why their distribution is associated with cracks is not clear yet. 

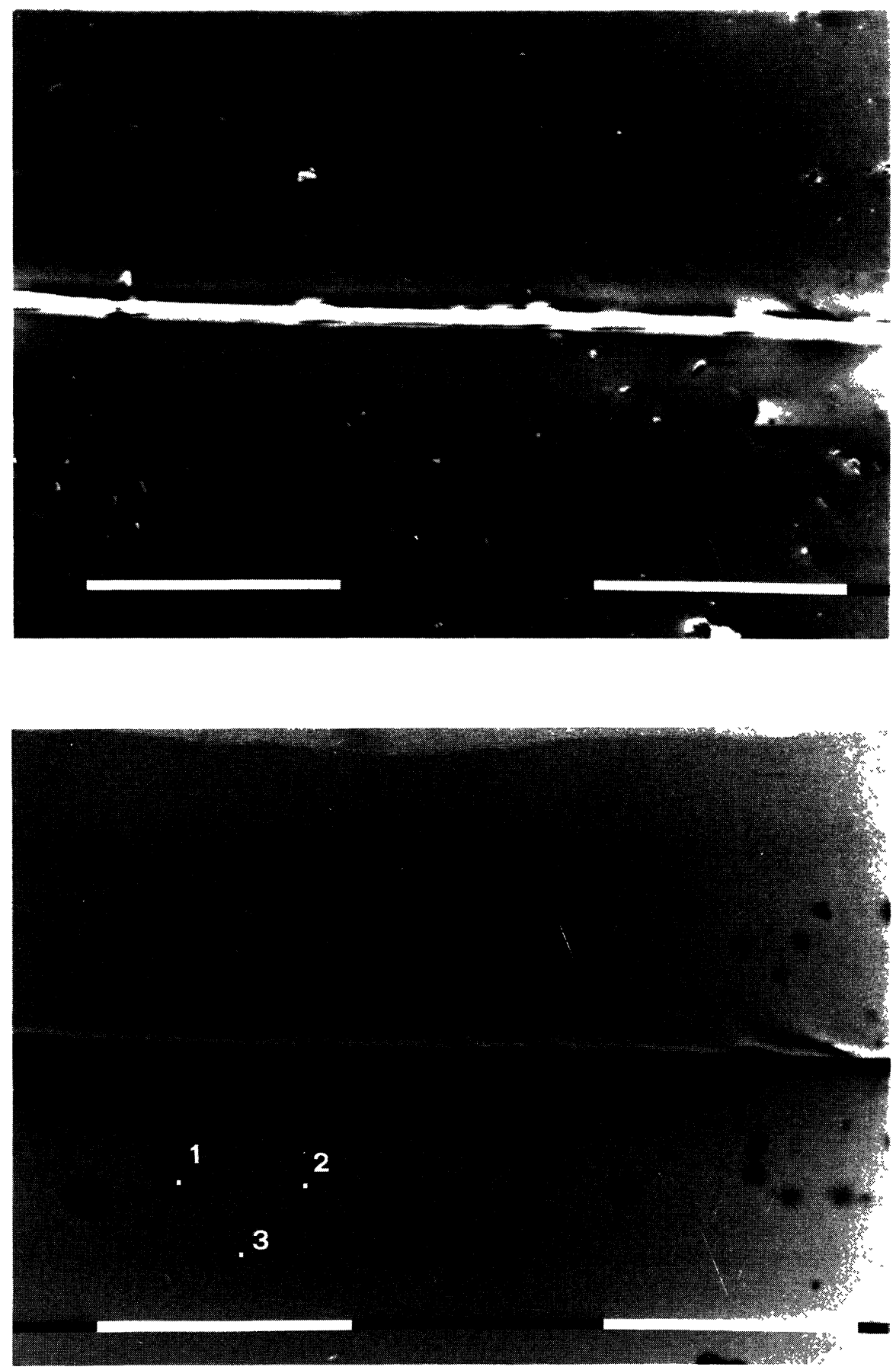

Fig. 6. - Sample type C. a) SE image showng lenucular shaped details (gas bubbles) and a crack. The bubbles are formed underneath the carbon coated surface and are related to deposits with carbon. b) BSE image showing the weak signal coming from the deposits. 1.2.3 indicate areas where WEDS has been performed. Marker $=100 \mu \mathrm{m}$. 
$B A=C-B \cup B B L E$

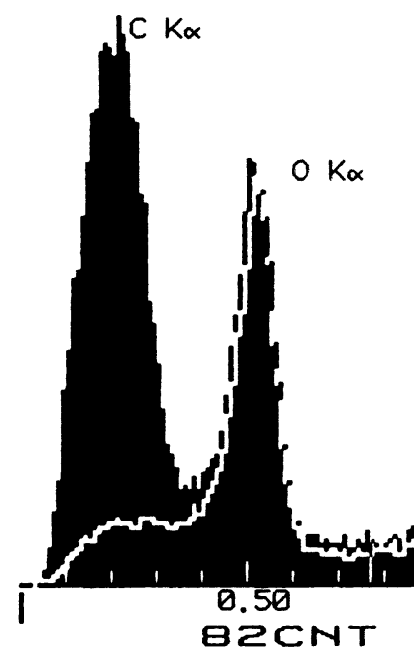

:C-MATRIX

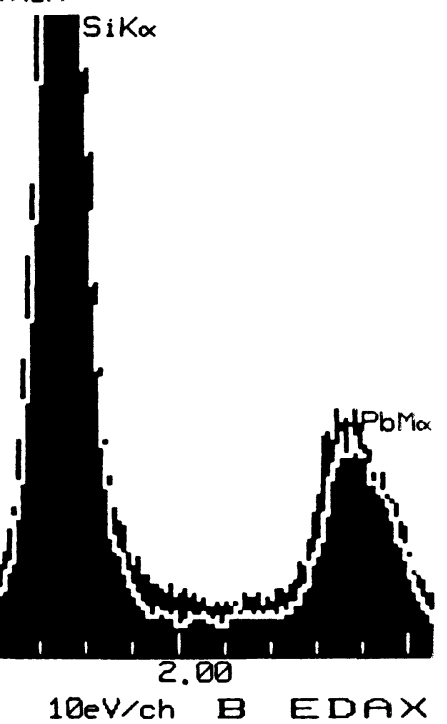

Fig. 7. - Superposition of two WEDS spectra obtained from a deposit (dark spectrum) and the surrounding carbon coated matrix (white spectrum). The presence of $\mathrm{C}$ in the deposit is evident.

\section{Conclusions.}

By characterizing morphology and composition of various type of defects in lead glasses prepared for the fabrication of glassware of high quality it has been possible to clarify the origin of the defects, so that suitable modification of the fabrication process may reduce, if not eliminate, their presence. This is particularly true for the case of the refractory material which affects the optical quality of the glass.

All in all, this work has demonstrated the capability of a SEM equipped with an (W)EDS for problem solving of defect characterization in lead glasses. The modern microscopes, in fact, offer both facilities for imaging by means of high efficiency BSE, for quantitative energy dispersive X-ray microanalysis and for qualitative low atomic number elements detection by means of Windowless EDS.

\section{Acknowledgements.}

The author thanks C.A.L.P. Chemical Lab. (Siena, Italy) for kindly providing glass specimens and standards, Dr E. Jarosewich U.S.N.M. (Washington, D.C.) for the supply of natural standards. Philips Analytical (Milan, Italy) is also thanked for kindly providing a MFD-BSE detector. Ministry of Public Education (MPI), Rome, is acknowledged for financial support. 


\section{References}

[1] OmaR A.A., ElShENnAWI A.W., Microscopy and genesis of some stones in commercial glass-ware, Sprechsaal 119 (1986) 368-371.

[2] SRIVASTAVA R.C., Some problems of stones in glasses, Glass Udyog 15 (1986) 17-21.

[3] BUCHMAYER P., Colour picture atlas of stones and inclusions in glass (Oberland Glas Editor, Bad Wurzach DDR, 1989).

[4] HUGES M.C., WONSIDLER D.R., Chemical and electron microprobe analysis of borophospho-silicate and phosphosilicate glasses, J. Electrochem. Soc. 134 (1987) 1488-94.

[5] OBORI K., SHIMIZU R., OURA T., ICHIMURA S., Quantitative microanalysis of individual particulates. Electron probe microanalysis of NBS-glass particulates, J. Appl. Phys. 54 (1983) 150-154.

[6] WAKABAYASHI H., YONEDA S., Quantitative analysis for ion-exchanged glass containing three kinds of alkalis by electron microprobe, J. Ceram. Soc. 92 (1984) 405-9.

[7] MURR L.E., Electron and ion microscopy and microanalysis: principles and applications (Marcel Dekker Inc. New York and Bale, 1982).

[8] LLOYD G.V., The atomic number and crystallographic contrast images in the SEM: a review of backscattered electron techniques, Min. Mag. 51 (1987) 3-19.

[9] CHANDLER J.A., X-ray microanalysis in the electron microscope, in: Practical Methods in the Electron Microscope, A.M. Glauert Ed., vol. 5, Part II (North Holland, Amsterdam, 1977).

[10] Philips MFD-BSD and Solid State detectors.

[11] REIMER L., Scanning Electron Microscopy, 45 (Springer Verlag, Berlin, 1985).

[12] NEwBURY D.E., JOY D.C., ECHLIN P., FIORI C.E. and GolDSTEIN J.I., Advanced Scanning Electron Microscopy and X-ray Microanalysis (Plenum Press, New York, 1987).

[13] MYCKLEBUST R.L., FIORI C.E., HEINRICH K.F.J., Frame C, a compact procedure for quantitative energy-dispersive electron probe x-ray analysis, NBS Techn. Note, 1106 (Washington, U.S. Government Printing Office) (1979) p.106.

[14] NBS Gaithersburg, MD, Reference standard $\mathrm{N}^{\circ} 89$.

[15] JAROSEWICH E., NELSEN J.A., NORBERG Julie A., Reference samples for electron microprobe analysis, Geostandards Newslett. 4 (1980) 43-47.

[16] C.A.L.P. (Siena Italy) private communication. 